\title{
KEINGINAN UNTUK BERTAHAN ATAU KELUAR DARI ORGANISASI DI UNIT BISNIS UMY
}

\author{
Isthofaina Astuty 1 \\ Manajemen, Universitas Muhammadiyah Yogyakarta \\ Yogyakarta, Indonesia \\ isthofainaastuty@umy.ac.id
}

\begin{abstract}
In an effort to improve the professionalism of Micro, Small and Medium Enterprises in managing their business, each leader of Micro, Small and Medium Enterprises must be able to predict the desire of Micro, Small and Medium Enterprises to leave the organization (turnover intention). Turnover intention will have an impact on human resource management and further impact on the ability of organizations to compete with other organizations. The high level of willingness to move in MSMEs is one of the factors reported by several previous studies as HR problems that affect the success of MSMEs.

The factors referred to by previous studies as factors that are able to predict turnover intention are job satisfaction and organizational commitment. So, the aim of the research is to examine the effect of job satisfaction as an antecedent variable on organizational commitment to turnover intention, with organizational commitment as an intervening variable.

In this research, some instruments were used: Mienisotta Satisfaction Questionnaire (MSQ) to measure job satisfaction, Allen and Mayer (1990) to measure organizational commitment, and Hom and Griffieth (1991) to measure turnover intention. Path Analysis wa used to analyze the data.

The results showed that job satisfaction is an antecedent variable of organizational commitment, but not an antecedent variable of turnover intention. Whereas, organizational commitment is not an intervening variable for the correlation between job satisfaction and turnover intention.
\end{abstract}

Keywords : Turnover intention, Job satisfantion, Organizational Commitment

\begin{abstract}
Abstrak
Dalam upaya meningkatkan profesionalisme Usaha Mikro Kecil Dan Menengah dalam mengelola usahanya, maka setiap pemimpin Usaha Mikro Kecil Dan Menengah harus mampu memprediksikan keinginan karyawan Usaha Mikro Kecil Dan Menengah untuk meninggalkan organisasi (turnover intention). Turnover intention akan berdampak pada pengelolaan sumberdaya manusia dan lebih lanjut berdampak pada kemampuan organisasi untuk bersaing dengan organisasi lain . Tingginya tingkat keingian untuk berpindah di UMKM adalah salah satu faktor yang dilaporkan oleh beberapa penelitian terdahulu sebagai masalah SDM yang mempengaruhi keberhasilan UMKM.
\end{abstract}

Faktor-faktor yang dirujuk penelitian terdahulu sebagai faktor yang mampu memprediksi keinginan berpindah adalah kepuasan kerja dan komitmen organisasional. Oleh karena itu tujuan yang ingin dicapai dalam penelitian adalah untuk menguji pengaruh kepuasan kerja sebagai variabel anteseden komitmen organisasial terhadap keinginan berpindah dari organisasi, dengan komitmen organisasi sebagai variabel intervening. Penelitian ini sejalan dengan pengembangan riset dalam Road Map 
Jurnal Manajemen Bisnis, Vol 10. No.1, Maret 2019, E-ISSN:2622-6308 P-ISSN:2086-8200

Website: http://journal.umy.ac.id/index.php/mb

DOI:10.18196/mb.10166

Manajemen 2018-2019 yakni identifikasi kompetensi manajerial yang dibutuhkan untuk menghadapi MEA dalam lingkup UMKM.

Untuk menjawab tujuan penelitian digunakan instrumen dari Miniesotta Satisfaction Quetionaire (MSQ) untuk mengukur varabel kepuasan kerja, Allen dan Mayer (1990) untuk variabel komitmen organisasional dan instrumen dari Hom dan Griffieth (1991) untuk variabel keinginan berpindah serta menggunakan Analisis Jalur untuk menjawab tujuan penelitian.

Hasil penelitian menunjukkan bahwa kepuasan kerja menjadi variabel anteseden dari komitmen organisasi, tapi bukan merupakan variabel anteseden dari turnover intention, sedangkan komitmen organisasional juga bukan merupakan variabel internening dalam pengaruh kepuasan kerja terhadap turnover intention.

Kata Kunci: Kepuasan Kerja, Stres Kerja, Komitmen Organisasi , Keinginan untuk Berpindah (Turn Over Intention)

\section{PENDAHULUAN}

\section{Latar Belakang}

Di Indonesia Usaha Kecil Mikro dan Menengah (UMKM) mendapatkan perhatian yang lebih dari pemerintah Indonesia. Hal ini terbukti dengan adanya departemen khusus yang menangani segala bidang yang berhubungan dengan UMKM, yakni Kementerian UMKM dan Koperasi. Beberapa alasan yang mendasari kebijakan ini adalah: Kontribusi UMKM dalam PDM sebesar 61,41 \%, Penyerapan tenaga kerja sektor UMKM mencapai 96,71 $\%$, dan sumbangan eksport non migas dari UMKM sebesar 15,73 \% (BPS, 2015). Namun demikian permasalahan UMKM terkait dengan profesionalisme dan manajemen organisasi masih menjadi kendala besar tujuan pemerintah untuk meningkatkan peran UMKM dalam perekonomian dan kesejahteraan masyarakat Indonesia.

Hal ini sejalan dengan isi dari Arah Kebijakan Bidang Koperasi, Usaha Mikro, Kecil dan Menengah oleh yang disampaikan oleh Ir Agus Muharam M.Sp (Sekretaris Kementrian Koperasi Dan UKM) di Denpasar pada tanggal 23 Maret 2017 bahwa permasalahan UMKM dan koperasi selama ini adalah berkisar dalam aspek : SDM, pembiayaan, pemasaran, manajemen dan tehnologi serta kelembagaan. http://www.depkop.go.id

Hal senada juga dilaporkan oleh BI bekerjasama dengan LPPI yang menyusun suatu Profil Bisnis UMKM 2015, dimana salah satu hal yang dilaporkan adalah adanya kendala internal UMKM (yang berbentuk Modal, SDM, Hukum, Akuntabilitas ), serta kendala eksternal (yang berbentuk iklim usaha, infrastruktur,akses). http://www.bi.go.id.

Sumberdaya Manusia menjadi salah satu kendala utama keberhasilan suatu UMKM, selain masalah keterbatasan kemampuan pemilik atau pemimpim UMKM Keterbatasan SDM berakibat pada tidak berkembangnya UMKM yang mereka pimpin atau stagnan, bahkan 
Jurnal Manajemen Bisnis, Vol 10. No.1, Maret 2019, E-ISSN:2622-6308 P-ISSN:2086-8200

Website: http://journal.umy.ac.id/index.php/mb

DOI:10.18196/mb.10166

banyak diantaranya yang terpaksa gulung tikar. Permasalahan SDM lain yang muncul adalah tingginya pergantian karyawan atau sering dikenal dengan istilah turnover intention, seperti yang dilaporkan oleh Rama Apriyani (2017), Roland Sukwadi dan Melkha Medina (2014) serta Lukman Halimudin (2014).

Rama Apriyani (2017) dalam penelitiannya yang berjudul “Pengaruh Komitmen, Kompensasi, Konflik terhadap Turnover Intention Karyawan (Studi Kasus di UMKM Bakpia Paguyupan PWE Laris Manis )" di Purwodiningratan Kalurahan Ngampilan Yogyakarta melaporkan bahwa menurut ketua paguyuban industri bakpia, yakni Bapak Joni Purwanto, di paguyuban Laris Manis sering terjadi keluar masuknya karyawan dikarenakan masalah loyalitas dan konflik. Begitu juga dengan Roland Sukwadi dan Meilkha Medina ( 2014) dalam penelitiannya yang berjudul "Faktor-Faktor yang Mempengaruhi Kinerja dan Turnover Intention Karyawan Usaha Kecil dan Menengah" melaporkan bahwa tingkat turnover intention di UKM Sungkai Indah di Jatinegara Kaum Jakarta Timur yang bergerak di bidang mebeler rata-rata perbulan $20 \%$. Juga penelitian dari Lukman Halimudian (2014) yang berjudul “Penurunan Turnover Intention Melalui Peningkatan Kepuasan Kerja Karyawan Pia Apple Pie Bogor " yang melaporkan bahwa rata - rata tingkat turnover di Pia Apple Pie Bogor adalah $12 \%$.

Masalah turnover adalah masalah kritis yang harus segera ditangani oleh pemilik atau pimpinan UMKM. Satu sisi, tinggi angka ini mengidikasikan bahwa organisasi tidak mampu mengelola SDM dengan baik sehingga karyawan tidak merasa nyaman bekerja di organisasi. Angka ini juga menggambarkan bahwa organisasi tidak menunujukkan kinerja ekonomi yang optimal sehingga karyawan merasa tidak aman bekerja di dalam organisasi. Di sisi lain, tingginya keinginan karyawan untuk meninggalkan organisasi akan mudah memicu munculnya keputusan untuk keluar dari organisasi yang selanjutnya akan berdampak pada terganggunya aktivitas operasional UMKM, ketidakmampuan organisasi untuk memenuhi kebutuhan pelanggan, dan lebih jauh akan menimbulkan citra negatif UMKM di mata masyarakat.

Namun dampak negatif adanya tidak hanya berhenti pada aspek itu saja, realita menunjukkan bahwa ketika karyawan memutuskan keluar dari organisasi, maka konsekuensi lain adalah naiknya biaya pengelolaan SDM organisasi dikarenakan organisasi harus melakukan rekrutmen dan seleksi ulang untuk mendapatkan karyawan pengganti, meningkatnya biaya pelatihan untuk karyawan pengganti ,serta biaya kerusakan produk atau 
Jurnal Manajemen Bisnis, Vol 10. No.1, Maret 2019, E-ISSN:2622-6308 P-ISSN:2086-8200

Website: http://journal.umy.ac.id/index.php/mb

DOI:10.18196/mb.10166

perlengkapan dikarenakan dipekerjakannya karyawan pengganti yang belum sekualitas karyawan lama. Masalah waktu juga harus dipertimbangkan, khususnya berkaitan dengan kebutuhan waktu untuk melakukan rekrutmen dan seleksi yang tidak singkat untuk mendapatkan karyawan yang sesuai dengan kriteria dan kebutuhan UMKM serta waktu yang dibutuhkan untuk melatih karywan pengganti yang cukup lama sehingga bisa mendapatkan karyawan yang berkualitas. Oleh karena itu penting bagi setiap UMKM untuk memprediksikan tingkat turnover intention di lingkup organisasi masing-masing agar tidak mengalami dampak negatif tersebut.

Dari beberapa penelitian sebelumnya menunjukkan bahwa banyak faktor yang menjadi anteseden terjadinya turnover intention, seperti gaya kepemimpinan, kompensasi, keterlibatan kerja, konflik dan stres. Namun banyak penelitian yang menunjukkan bahwa kepuasan kerja dan komitmenlah yang menjadi faktor utama penyebab terjadinya turnover intention. Penelitian dari Azeez,R.O.,Jeyeoba F, Adeaye A.O. (2016), Souvar Y, Setti S.A, Boussahmine A (2016) melaporkan adanya hubungan anatara kepuasan kerja ke keinginan berpindah. Penelitian dari Dewa Gede EKP dan Ida Bagus KS (2016), Yang John Yun (2016), serta Ciemike K, Choi SL, Hapiza A (2017) yang menunjukkan adanya hubungan antara komitmen organisasi ke keinginan untuk bertahan (turnover intention). Jadi ketika seorang karyawan merasa senang dengan aspek-aspek pekerjaan (puas) maka karyawan akan cenderung tidak menginginkan untuk meninggalkan organisasi (turnover intention rendah), di sisi lain ketika karyawan memiliki perasaan positif pada organisasi dan bangga pada organisasi (komit) maka merekapun cenderung untuk tetap bertahan di organisasi (turnover intention rendah).

\section{Rumusan Masalah}

Keinginan untuk pindah dari organisasi akan berdampak pada banyak aspek manajemen organisasi, baik dalam bidang SDM, keuangan, operasional organisasi serta image organisasi. Untuk mengelola tingkat keinginan berpindah bisa dimulai dengan menciptakan kondisi kerja yang menyenangkan (kepuasan kerja) sehingga karyawan akan memiliki penilaian positif pada organisasi, bangga pada organisasi (komitmen organisasi) dan selanjutnya karyawan tidak memiliki keinginan untuk meninggalkan organisasi (turnover intention). Oleh karena itu rumusan masalah yang diajukan adalah: Bagaimana model 
Jurnal Manajemen Bisnis, Vol 10. No.1, Maret 2019, E-ISSN:2622-6308 P-ISSN:2086-8200

Website: http://journal.umy.ac.id/index.php/mb

DOI:10.18196/mb.10166

memprediksi keinginan karyawan untuk bertahan atau pindah dari organisasi melalui kepuasan kerja yang dimediasi oleh komitmen organisasi?

\section{Tujuan Penelitian}

Tujuan penelitian ini adalah: Memprediksi keinginan karyawan untuk bertahan atau pindah dari organisasi melalui kepuasan kerja yang dimediasi oleh komitmen organisasi. Penelitian ini penting dilakukan dengan pertimbangan bahwa masalah turnover intention adalah salah satu masalah kritis dalam pengelolaan SDM di UMKM yang sering terjadi namun belum mendapatkan perhatian serius dari pimpian UMKM. Kasus turnover intention ini berakibat pada menurunnya kualitas UMKM dikerenakan kualitas SDM yang tidak bisa dipertahankan dengan baik karena tingginya tingkat keluar masuknya karyawan UMKM.

\section{LANDASAN TEORI}

\section{Kepuasan Kerja}

Kepuasan kerja menurut Locke adalah keadan emosional seseorang yang positif atau menyenangkan yang merupakan dampak dari penilaian seseorang akan pekerjaan atau pengalaman kerja (Luthan, 2006). Jadi kepuasan menyangkut: respon emosional sesorang terhadap aspek-aspek pekerjaan, seberapa baik outcome dari pekerjaan memenuhi harapan, serta beberapa sikap yang saling berkaitan satu dengan yang lain. Menurut Robbin dan Judge (2017) kepuasan kerja menggambarkan suatu perasaan positif tentang pekerjaan yang dihaslakn dari suatu evaluasi dari karakteristik-karakteristiknya.

Luthans (2006) menyatakan ada lima dimensi pekerjaan telah diidentifikasi untuk merepresentasikan karakteristik pekerjaan yang paling penting dimana karyawan memiliki respon afektif, kelima dimensi tersebut adalah: (1) Pekerjaan itu sendiri (tugas yang menarik, kesempatan untuk belajar, dan kesempatan untuk menerima tanggung jawab dari atasannya). (2) Gaji (penghargaan yang sesuai atau pantas dibandingkan dengan orang lain di dalam organisasinya). (3) Kesempatan promosi atau perkembangan karir/jabatan. (3) Pengawasan (bantuan teknis dan dukungan perilaku terhadap bawahan). (4) Rekan kerja (pandai secara teknis dan mendukung secara social). 
Jurnal Manajemen Bisnis, Vol 10. No.1, Maret 2019, E-ISSN:2622-6308 P-ISSN:2086-8200

Website: http://journal.umy.ac.id/index.php/mb

DOI:10.18196/mb.10166

\section{Komitmen Organisasi}

Komitmen organisasi merujuk kepada loyalitas seseorang kepada perusahaan berdasar penerimaaan seseorang akan sasaran dan nilai perusahaan, kemauan seseorang untuk berusaha menjadi bagian dari perusahaan serta keinginan seseorang untuk tetap bertahan di dalam perusahaan (dikutip oleh Riggio, 1990 dari Porter et all 1974). Menurut Moday,et all, 1982 komitmen organisasi adalah kekuatan individu terhadap organisasi dan keterlibatan kepada organisasi (dalam Vanderberg dan Lance, 1992).

Dalam penelitian ini konsep komitmen yang dipakai adalah konsep komitmen dari Mayer, Allen dan Smith (1993) yang mendefenisikan komitmen sebagai konsep yang multidimensional. Komitmen organisasional adalah komitmen sebagai suatu keterikatan afektif pada organisasi (afecctive commitment), komitmen sebagai pengorbanan yang dipersepsikan yang dikaitkan dengan tindakan individu meninggalkan organisasi (continuance commitment) dan komitmen sebagai suatu keyakinan untuk tetap tinggal di organisasi (normative commitment).

Ada lima indikator dari komitmen organisasi menurut Luthans (2006), diantaranya adalah:

\section{Menjadi bagian dari organisasi}

Indikator pertama karyawan yang memiliki komitmen organisasi adalah mempunyai rasa bagian dari organisasi. Karyawan merasa dirinya sudah menyatu dengan organisasi sehingga dia peduli terhadap organisasinya.

\section{Kebanggaan}

Karyawan yang bangga terhadap perusahaannya juga diindikasikan memiliki komitmen organisasi. Ketika karyawan komitmen terhadap organisasinya dia akan selalu memiliki rasa bangga terhadap yang ada dalam perusahaannya.

\section{Kepedulian}

Karyawan yang memiliki komitmen organisasi yang tinggi akan mempunya rasa peduli terhadap organisasi. Karyawan akan selalu memperhatikan kebijakan dan hal lainnya yang berkaitan dengan organisasi demi tujuan organisasi.

\section{Hasrat yang kuat}

Karyawan yang memiliki komitmen organisasi yang tinggi cenderung mempunyai hasrat yang tinggi juga untuk kepentingan organisasinya. 
Jurnal Manajemen Bisnis, Vol 10. No.1, Maret 2019, E-ISSN:2622-6308 P-ISSN:2086-8200

Website: http://journal.umy.ac.id/index.php/mb

DOI:10.18196/mb.10166

\section{Kepercayaan yang kuat}

Seorang karyawan yang memiliki komitmen organisasi yang tinggi akan mempunyai kepercayaan terhadap organisasinya. Karyawan akan percaya terhadap kebijakan perusahaan yang diterapkan.

\section{Keinginan Berpindah}

Keinginan berpindah atau Turnover Intention adala niatan yang timbul dalam diri seseorang untuk pindah atau meninggalkan organisasi baik dalam wujud pemberhentian ataupun pengunduran diri. (Hom and Griffeth, 1991). Mobley et al., 1978 (dalam Halimah dkk., 2016) berpendapat keinginan pindah kerja menggambarkan kecenderungan atau niat seseorang untuk berhenti bekerja dari suatu perusahaan tanpa paksaan ataupun pindah dari satu tempat ke tempat kerja yang lain sesuai dengan pilihannya sendiri atau cocok.

Ada tiga indikator pengukuran turnover intention menurut Mobley et al,. 1978 (dalam Halimah dkk., 2016) terdiri atas: (1) Memikirkan untuk keluar (Thinking of Quitting). Pemikiran seorang individu untuk keluar dari pekerjaan atau tetap berada di lingkungan pekerjaann yang sedang dijalankan. (2) Pencarian alternatif pekerjaan (Intention to search for alternatives). Menggambarkan perasaan seorang individu yang berkeinginan untuk mencari pekerjaan pada organisasi lain atau alternatif pekerjaan diluar perusahaannya yang dirasa lebih baik. (3) Niat untuk keluar (Intention to quit). Mencerminkan niat seorang individu untuk keluar dari perusahaannya.

\section{Pengaruh Kepuasan Kerja Ke Komitmen Organisasi}

Kepuasan kerja menggambarkan penilaian positif seseorang akan aspek-aspek pekerjaan. Ketika seseorang menilai bahwa kompensasi yang diterima memenuhi harapan mereka, rekan kerja berperilaku positif dan saling mendukung pekerjaan satu dengan yang lain, pemimpinan bisa memberikan contoh dalam bekerja maka karyawan akan cenderung memberikan nilai positif pada pekerjaan, dalam hal ini dia akan merasa puas pada pekerjanya. Pada saat seseorang bekerja dengan perasaan positif pada pekerjaan mereka maka karyawan akan cenderung meningkatkan perasaan positif pada organisasi yang telah memberikan kesempatan kepada mereka untuk mendapatkan pekerjaan. Dengan kalimat 
Jurnal Manajemen Bisnis, Vol 10. No.1, Maret 2019, E-ISSN:2622-6308 P-ISSN:2086-8200

Website: http://journal.umy.ac.id/index.php/mb

DOI:10.18196/mb.10166

lain, ketika seseorang puas dengan pekerjaan yang menjadi tanggungjawabnya maka karyawan akan cenderung memiliki komitmen pada organisasi. Sejalan dengan penjelasan ini adalah beberapa penelitian yang memberikan bukti empiris bahwa kepuasam kerja berpengaruh pada komitmen organisasional. Penelitian dari Emdy Mahardika Putra dan I Made Artha Wibawa (2015), Ni Luh Sintia Dewi dan I Wayan Suana (2016) serta Ming-Jiuan $\mathrm{Wu}, 2013$. Oleh karena itu hipotesis 1 yang diajukan adalah:

H1: Terdapat pengaruh positif kepuasan Kerja terhadap Komitmen Organisasional.

\section{Pengaruh Kepuasan Kerja ke Keinginan Berpindah}

Karyawan yang memiliki sikap positif kepada pekerjaan adalah karyawan yang menilai bahwa aspek-aspek pekerjaan yang menjadi tanggungjawabnya telah sesuai dengan keinginan mereka dan telah memberikan kepuasan kerja. Perasaan positif pada pekerjaan ini menjadi dasar bagi karyawan untuk tetap bertahan dalam organisasi dan tidak memeliki keinginan untuk meninggalkan organisasi .Dengan kalimat lain, ketika seseorang puas dengan pekerjaan yang menjadi tanggungjawabnya maka karyawan akan cenderung memiliki tingkat keinginan meninggalkan organisasi yang rendah. Sejalan dengan penjelasan ini adalah beberapa penelitian yang memberikan bukti empiris bahwa kepuasam kerja berpengaruh pada keinginan berpindah dari organisasi., seperti Rohani Salleh, Mishaliny Sivadahasan Nair, and Haryanni Harun (2012), Arya Wira Suta dan I Wayan Gede Supartha (2016), Yang,Jonh Yun (2016), Yong Lu, Xiao-Min Hu, Xiao-Liang Huang, Xiao-Dong Zhuang (2017), serta Ciemeke Kingsley Ciedu,Choi Sang Long, Hapriza Azhari (2017). Oleh karena itu hipotesis 2 yang diajukan adalah:

H2: Terdapat pengaruh negatif kepuasan Kerja terhadap Keinginan Berpindah (turnover intention).

\section{Pengaruh Komitmen Ke Keinginan Berpindah}

Karyawan yang memiliki sikap positif kepada organisasi adalah karyawan yang menilai bahwa aspek-aspek organisasi yang menjadi tanggungjawabnya telah sesuai dengan keinginan mereka dan telah memberikan kepuasan kerja. Perasaan positif pada organisasi ini menjadi dasar bagi karyawan untuk tetap bertahan dalam organisasi dan tidak memeliki keinginan untuk meninggalkan organisasi .Dengan kalimat lain, ketika seseorang puas dengan organisasi ymaka karyawan akan cenderung memiliki tingkat keinginan 
Jurnal Manajemen Bisnis, Vol 10. No.1, Maret 2019, E-ISSN:2622-6308 P-ISSN:2086-8200

Website: http://journal.umy.ac.id/index.php/mb

DOI:10.18196/mb.10166

meninggalkan organisasi yang rendah. Sejalan dengan penjelasan ini adalah beberapa penelitian yang memberikan bukti empiris bahwa kepuasam kerja berpengaruh pada keinginan berpindah dari organisasi, seperti : Rohani Salleh, Mishaliny Sivadahasan Nair, and Haryanni Harun (2012), Yang,Jonh Yun (2016) ,Dewa Gede Eka Kresna Putra dan Ida Bagus Ketut Surya (2016), Ni Nyoman Ayu Dyantini dan I Gusti Ayu Manuati Dewi (2016) , Ciemeke Kingsley Ciedu,Choi Sang Long, Hapriza Azhari (2017) Oleh karena itu hipotesis 3 yang diajukan adalah:

H3: Terdapat pengaruh negatif Komitmen Organisasional terhadap Keinginan Berpindah (turnover intention).

\section{Pengaruh Kepuasan Kerja Terhadap Keinginan Berpindah dengan Komitmen Organisasi sebagai variabel mediasi}

Setiap karyawan yang merasakan nyaman di tempat kerja, senang dengan kondisi kerja, merasakan mendapatkan dukungan dari supervisor dan rekan kerja akan berperilaku positif pada organisasi dengan cara menunjukkan berbagai kontribusi dan pengorbanan bagi organisasi, loyalitas pada organisasi, dan pada akhirnya akan cenderung bertahan dalam organisasi dan tidak memiliki keinginan untuk pinah dari organiasasi. Lebih jelasnya adalah ketika karyawan merasakan puas pada pekerjaan maka dia akan menujukkan komitmen pada organisasi dan pada akhirnya akan menurunkan tingkat keinginan berpindah dari organisasi. Hal senada juga ditemukan oleh beberapa peneliti terdahulu, seperti : Emdy Mahardika Putra dan I Made Artha Wibawa (2015), Dewa Gede Eka Kresna Putra dan Ida Bagus Ketut Surya (2016), Rini Ratna Nafita Sari, Armanu, dan Eka Afnan (2016). Hasil penelitian menunjukkan terdapat pengaruh tidak langsung antara kepuasan kerja terhadap turnover intentions melalui komitmen organisasional secara signifikan, dengan kalimat lain komitmen organisasional mampu memediasi secara negatif dan signifikan pengaruh kepuasan gaji terhadap turnover intention. Oleh karena itu hipotesis 4 yang diajukan adalah:

H4: Terdapat pengaruh kepuasan kerja terhadap keinginan berpindah (turnover intention) melalui komitmen organisasional 
Jurnal Manajemen Bisnis, Vol 10. No.1, Maret 2019, E-ISSN:2622-6308 P-ISSN:2086-8200

Website: http://journal.umy.ac.id/index.php/mb

DOI:10.18196/mb.10166

Model penelitian dalam penelitian ini dapat digambarkan sebagai berikut:

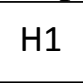

H3
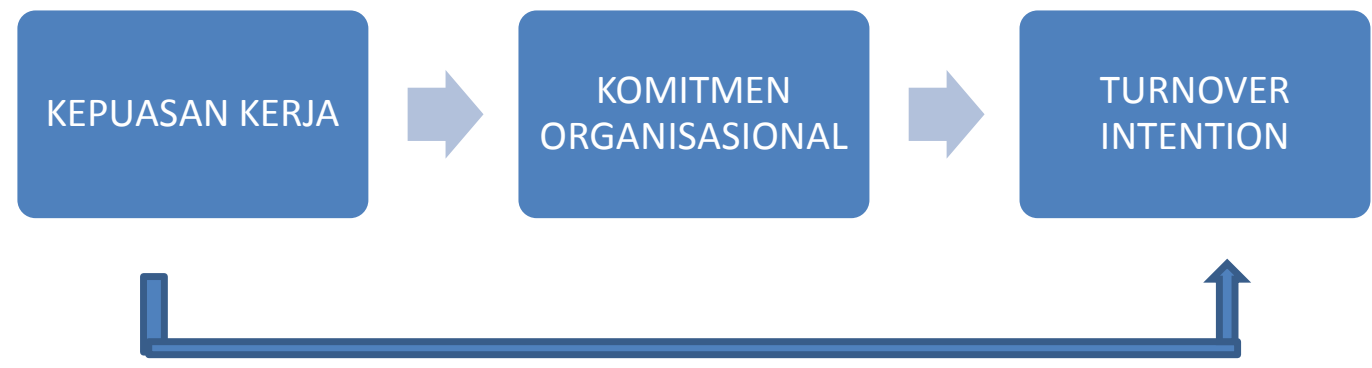

$\mathrm{H} 2$

\section{Gambar 1. Model Penelitian}

Berdasarkan model penelitian di atas maka dapat diuraikan hipotesis penelitian sebagai berikut:

H1 : Kepuasan kerja berpengaruh positif dan signifikan terhadap komitmen organisasi

H2 : Kepuasan kerja berpengaruh negatif dan signifikan terhadap keinginan berpindah

H3 : Komitmen organisasi berpengaruh negatif dan signifikan terhadap turnover intention

H4 : Kepuasan organisasi berpengaruh negatif dan signifikan terhadap turnover intention melalui komitmen organisai

\section{METODE PENELITIAN}

Penelitian ini menggunakan pendekatan kuantitatif. Data yang digunakan dalam penelitian ini adalah data primer, yakni data mengenai kepuasan kerja, komitmen organisasi, serta keinginan untuk meninggalkan atau tetap bertahan di organisasi, sedangkan metode pengumpulan data dengan teknik survei melalui penyebaran kuesioner.

\section{Obyek Dan Subyek Penelitian}

Obyek penelitian adalah Usaha Mikro Kecil Menengah (UMKM) dibawah kendali PT UMAT UMY, dalam hal ini adalah Sportorium UMY, UMY BOGA, AUTOCARE dan UMY TIRTA. Subyek yang dipilih adalah karyawan dan staf UMKM Sample penelitian yang dipilih adalah semua karyawan Usaha Mikro Kecil Menengah (UMKM) di 4 unit dibawah PT UMY UMY. Jadi tehnik sampel yang dipakai adalah tehnik sensus. 
Jurnal Manajemen Bisnis, Vol 10. No.1, Maret 2019, E-ISSN:2622-6308 P-ISSN:2086-8200

Website: http://journal.umy.ac.id/index.php/mb

DOI:10.18196/mb.10166

\section{Definisi Operasional Variabel}

Variabel yang dipakai dalam penelitian ini adalah variabel kepuasan kerja dan komitmen organisasi sebagai variabel dependent, variabel stres sebagai variabel mediasi serta variabel keinginan berpindah sebagai variabel independen.

\section{Kepuasan Kerja (dependen)}

Kepuasan kerja menggambarkan perasaan positif sesorang kepada aspek-aspek pekerjaan. Dalam penelitian pengukuran varabel kepuasan kerja mengunakan model Minnisota Satisfaction Questionaire (MSQ) yang terdiri dari 20 indikator kerja yang dijabarkan dalam 20 item pertanyaan untuk edisi pendeknya.

\section{Keinginan Meninggalkan Organisasi (independen)}

Keinginan meninggalkan organisasi adalah niatan yang dimiliki seseorang untuk meninggalkan organisasi atau mencari pekerjaan lain di tempat lain. Pengukuran variabel ini menggunakan model dari Hom dan Graffieth 1990 yang terdiri dari 5 pertanyaan.

\section{Komitmen Organisasi (Intervening)}

Komitmen organisasi sebagai suatu konstruk psikologis yang menggambarkan karakteristik hubungan anggota organisasi dengan organisasinya dan berimplikasi kepada keputusan individu untuk mempertahankan keanggotaannya dalam berorganisasi (Meyer dan Allen, 1991). Pengukuran variabel ini dikembangkan oleh orang sama dengan tiga komponen yaitu Affective Commitment, Continuance Commitment, dan Normative Commitment (Meyer dan Allen, 1993). Terdapat 18 item pertanyaan dari variabel komitmen organisasional yang meliputi 6 item pertanyaan untuk setiap dimensinya.

\section{Analisis Data}

Teknik analisis data yang dipilih adalah menggunakan Path Analysis (Analisis Jalur).

\section{HASIL PENELITIAN DAN PEMBAHASAN}

Kuesioner penelitian disebarkan mulai pertengahan bulan Juli sampai dengan akhir bulan Juli 2018 memperoleh hasil sebagai berikut. 
Jurnal Manajemen Bisnis, Vol 10. No.1, Maret 2019, E-ISSN:2622-6308 P-ISSN:2086-8200

Website: http://journal.umy.ac.id/index.php/mb

DOI:10.18196/mb.10166

Tabel 1. Laporan penyebaran kuesioner

\begin{tabular}{|c|c|c|c|}
\hline Binaan dari: & $\begin{array}{r}\text { Target } \\
\text { Jumlah }\end{array}$ & Realisasi & $\begin{array}{c}\text { Realisasi } \\
(\%)\end{array}$ \\
\hline SPORTORIUM & 15 & 15 & $100 \%$ \\
\hline UMY BOGA & 21 & 20 & $85 \%$ \\
\hline UMY TIRTA & 6 & 5 & $83 \%$ \\
\hline AUTOCARE & 3 & 3 & $100 \%$ \\
\hline Total & 45 & 43 & $95 \%$ \\
\hline
\end{tabular}

Mayoritas responden berasal dari UMY BOGA sebanyak $46 \%$ atau 20 orang dari 43 responden yang akhirnya mengembalikan kuesioner yang telah diisi dengan benar dan lengkap., baru setelah itu Sportorium sebanyak $35 \%$ atau 15 orang. Kondisi terjadi dikarenakan kedua unit layanan inilah yang memiliki jumlah staf dan karyawan terbanyak di PT UMAT UMY. Mayoritas responden adalah laki-laki (84 \%). Hal ini terjadi dikarenakan mayoritas staf dan karywan PT UMAT UMY adalah laki-laki.

Profile responden penelitian dilihat dari masa kerja menunjukkan bahwa $32 \%$ baru bekerja di unit layana sekitar 3,1 tahun sampai dengan 5 tahun dan hanya $19 \%$ responden yang memiliki masa kerja kurang dari 1 tahun. Bahkan jika dicermati lebih lanjut hampir 81 $\%$ responden memiliki masa kerja diatas 1 tahun, hal ini mengindikasikan bahwa mayoritas responden betah bekerja di unit layanan dibawah PT UMAT UMY . Dilihat dari sisi usis mayoritas responden berusia dibawah 40 tahun (63\%). Hal ini menunjukkan bahwa PT UMAT UMY memiliki pegawai yang berusia produktif sehingga bisa dikelola untuk bersaing demi kepuasan konsumen yang dilayani.

Dari hasil pengujian instrumen yang menggunakan metode product moment untuk melihat tingkat validitas intrumen menunjukkan bahwa dari 20 item pertanyanan Kepuasan kerja terdapat 3 dimensi yang tidak valid, 1 dimensi varaiebl komitmen organisasil tidak valid dan 1 dimensi variabel turn over intention tidak valid (Saya akan mempertimbangkan mengambil pekerjaan lain). Untuk uji reliabilitas ketiga variabel memiliki nilai yang reliabel. Adapun Deskripsi data penelitian disajikan sebagai berikut. 
Jurnal Manajemen Bisnis, Vol 10. No.1, Maret 2019, E-ISSN:2622-6308 P-ISSN:2086-8200

Website: http://journal.umy.ac.id/index.php/mb

DOI:10.18196/mb.10166

Tabel 2. Descriptive Statistics

\begin{tabular}{lcccc}
\hline & $\begin{array}{c}\text { TURN OVER } \\
\text { INTENTION }\end{array}$ & $\begin{array}{c}\text { KOMITMEN } \\
\text { ORGANISASIONAL }\end{array}$ & $\begin{array}{c}\text { KEPUASAN } \\
\text { KERJA }\end{array}$ \\
\hline \multirow{2}{*}{$\mathbf{N}$} & Valid & 43 & 43 & 43 \\
\cline { 2 - 5 } & Missing & 0 & 0 & 0 \\
\hline Mean & 2.6163 & 3.4501 & 3.7439 \\
\hline Std. Deviation & .53549 & .30292 & .35854 \\
\hline Minimum & 1 & 2 & 2 \\
\hline Maximum & 4 & 5 & 5 \\
\hline
\end{tabular}

Berdasar data diatas dapat dinyatakan bahwa nilai mean mendekati angka 3,5 kecuali variabel turn over intentionm yang nilainya hanya 2,6. Berdasar kriteria maka dapat dinyatakan bahwa responden penelitian memiliki tingkat kepusan kerja dan komitmen organisasional cukup baik mendekati baik, begitu juga dengan tingat turn over intention (keinginan untuk bertahan atau meninggalkan organisasi, dimana semakin rendah skore ini menunjukkan tingkat untuk bertahan di organisasi semakin baik dan keinginan untuk meninggalkan organisasi semakin kecil).

Hasil pengujian hipotesis menunjukkan bahwa dari 3 hipotesis pertama yang diuji dengan analisis regresi berganda sebanyak 1 kali dan regresi linier sederhana satu kali. Regresi pertama dilakukan dengan menghubungkan variabel kepuasan kerja dan varibel komitmen organisional sebagai dependent varibel terhadap turn over intention sebagai variabel independent. Regresi linier sederhana dilakukan dengan menghubungkan variabel kepuasan kerja sebagai depent varabel terhadap komitmen organisasional sebagai independent varaiebel.

Hipotesis ke empat diuji dengan analisis jalur (Path Analysis). Pengujian hipotesis penelitian disajikan dalam tabel berikut:

\section{Tabe1 3. Hasil Regresi Hipotesis 1}

\section{H1 : Pengaruh Kepuasan kerja ke Komitmen Organisasi}

\begin{tabular}{llr}
\hline \multicolumn{1}{c}{ Independent } & Komitmen Organisasi & \\
\hline Dependent & Kepuasan Kerja & 1.570 \\
\hline Beta & Constant & .537 \\
\cline { 2 - 3 } $\begin{array}{l}\text { Standardized } \\
\text { Coefficients) }\end{array}$ & Kepuasan Kerja & .000 \\
\hline Sig. & &
\end{tabular}


Jurnal Manajemen Bisnis, Vol 10. No.1, Maret 2019, E-ISSN:2622-6308 P-ISSN:2086-8200

Website: http://journal.umy.ac.id/index.php/mb

DOI:10.18196/mb.10166

Tabel 4. Hasil Regresi Hipotesis 2

\section{H2 : Pengaruh Kepuasan kerja ke Turnover Intention}

\begin{tabular}{llr}
\hline Independent & Turnover Intention & \\
\hline Dependent & Kepuasan Kerja & 1.570 \\
\hline Beta & Constant & -.010 \\
\cline { 2 - 3 } & Var Kepuasan & \\
\hline & Kerja & .943 \\
\hline
\end{tabular}

Tabel 5. Hasil Regresi Hipotesis 3

\section{H3 : Pengaruh Komitmen Organisasi ke Turnover Intention}

\begin{tabular}{llr}
\hline Independent & Turnover Intention & \\
\hline Dependent & Komitmen Organisasi & 3.564 \\
\hline Beta & Constant & -.155 \\
\cline { 2 - 3 } (Standardized & Var Komitmen & .319 \\
\hline Coefficients) & Organisasi &
\end{tabular}

Berdasar tabel 1 sampai dengan tabel 5. Menunjukkan bahwa: (1) Nilai yang menunjukkan pengaruh kepuasan kerja terhadap komitmen organisasional memberikan hasil yang signifikan dengan angka 0,537 ( $p$ value 0,00 ). (2) Nilai yang menunjukkan pengaruh kepuasan kerja terhadap turnover intention memberikan hasil yang tidak signifikan dengan angka - 0,010 (p value 0,937). (3) Nilai yang menunjukkan pengaruh komitmen organisasional terhadap turnover intention memberikan hasil yang tidak signifikan dengan angka -0,155 ( $p$ value 0,319$)$.

Dari hasil diatas dapat disimpulkan bahwa dari 3 hipotesis hanya hipotesis 1 yakni pengaruh kepuasan kerja terhadap komitmen organisasional yang sifnifikan, sedangkan hipotesis 2 dan 3 tidak sifnifikan, maka langkah terakhir untuk menentukan ada tidakanya pengaruh komitmen organisasional sebagai variabel interbening dengan Path Analysis tidak bisa dilanjutkan. Artinya hipotesis 4 ditolak.

Berdasar hasil, maka kesimpulan hipotesis: (1) Hipotesis 1, yang menyatakan bahwa kepuasan kerja berpengaruh positif terhadap komitmen organisasional didukung. (2) Hipotesis 2, yang menyatakan bahwa kepuasan kerja berpengaruh negatif terhadap turnover intention tidak didukung. (3) Hipotesis 3, yang menyatakan bahwa komitmen organisasional berpengaruh negatif terhadap turnover intention tidak didukung. (4) Hipotesis 4, yang 
Jurnal Manajemen Bisnis, Vol 10. No.1, Maret 2019, E-ISSN:2622-6308 P-ISSN:2086-8200

Website: http://journal.umy.ac.id/index.php/mb

DOI:10.18196/mb.10166

menyatakan bahwa ada pengaruh negatif kepuasan kerja terhadap turn over intention dengan komitmen organisasional sebagai variabel intervening tidak didukung.

\section{DAFTAR PUSTAKA}

Ciemeke K.C.,\&Choi S.L, \& Hapriza A. (2017). The relationship among Job Satisfaction, Comittment Organizational and Employees Turnover at Unilever Corporation in Nigeria

Dewa G.E.K.P, \& Ida B.K.S. (2016). Pengaruh Kepuasan Gaji Terhadap Turnover Intention Dengan Komitmen Organisasional Sebagai Mediasi Pada Rumah Sakit Umum Premagana.

Emdy M.P., \& I Made A.W. (2015). Pengaruh Kepuasan Kerja Terhadap Turnover Intention Dengan Komitmen Organisasi Sebagai Variabel Intervening Pada PT. Autobagus Rent Car Bali.

Halimah T.N, Fathoni A. \& Minarsih M.M. (2016). Pengaruh Jo in security, Kepuasan kerja Lingkungan Kerja terhadap turnover intention karywan Supermarket Gelael. Journal Of Management. Vol 2 no 2.

http://www.bi.go.id

http://www.depkop.go.id

Lukman H., (2014). Penurunan Turnover Intention Melalui Peningkatan Kepuasan Kerja Karyawan Pia Apple Pie Bogor, Skrisp Tidak Dipublikasikan, Program Sarjana Alih Jenis Manajemn Dapartemen Manajemen Fakultas Ekonomi dan Manajemen Istitute Pertanian Bogor

Luthan. (2006). Organizational Behavior. Seventh Edition. McGraw Hill.

Mayer J.P., Allen,N.J.,Smith, C.A. (1993). Commitment to Organization and Occupations: Extention and Test of a Three-Component Conceptualization, Jounal of Applied Psychology,19.

Ming-Jiuan W., (2013). Job Involvement, Job Stress, Job Satisfaction, and Organizational Commitment of University Faculty. Proceedings of Global Business Research Conference 78 November 2013, Hotel Himalaya. Kathmandu. Nepal. ISBN: 978-1-922069-35-1

Ni L.S.D. \& I Wayan S. (2016). Pengaruh Job Insecurity, Kepuasan Kerja Dan Keadilan Organisasi Terhadap Komitmen Organisasi Karyawan Kontrak.

Ni Made Tiya Jumani Monica dan Made Surya Putra, 2017 ,"Pengaruh Stres Kerja, Komitmen Organisasional, Dan Kepuasan Kerja Terhadap Turnover Intention".

Ni Nyoman A.D. \& I Gusti A.M.D. (2016). Pengaruh Komitmen Organisasional Dan Penilaian Kinerja Terhadap Turnover Intentio.

Rama A. (2017). Pengaruh Komitmen, Kompensasi, Konflik terhadap Turnover Intention Karyawan (Studi Kasus di UMKM Bakpia Paguyupan PWE Laris Manis, Penelitian tidak dipublikasikan, Fakultas Ekonomi Program Studi Manajemen Universitas PGRI Yogyakarta

Riggio,R.E. (1990), Introdustion to Industrial/Organizational Psychology, Scott, Foresman, Little Brown Higher Education,Iilnois

Rini R.N.S. Armanu, \& Eka A. 2016. Pengaruh Kepuasan Kerja Dan Komitmen Organisasional Terhadap Intention To Leave Pada Karyawan Produksi Mitra Produksi Sigaret (MPS) Ngoro-Jombang 
Jurnal Manajemen Bisnis, Vol 10. No.1, Maret 2019, E-ISSN:2622-6308 P-ISSN:2086-8200

Website: http://journal.umy.ac.id/index.php/mb

DOI:10.18196/mb.10166

Rohani S., Mishaliny S.N., \& Haryanni H. (2012). Job Satisfaction, Organizational Commitment, and Turnover Intention: A Case Study on Employees of a Retail Company in Malaysi. World Academy of Science, Engineering and Technology International Journal of Economics and Management Engineering Vol:6, No:12,

Ronald S.,Milkha M. (2014). Faktor_Faktor yang Mempengaruhi Kinerja dan Turnover Intention Karyawan Usaha Kecil dan Menengah, Jurnal Rekayasa Sistem Industri Vol 3,No 1, 2014

Vanderberg R,J., \& Lance,C.E. (1992). Examining the causalitas order of Job Satisfaion and Organizational Commitment. Journal of Management, 18.

Yang,Jonh Yun. (2016). The Relations of Stres, Job Satisfation, Organizational Commitment and Turnover Intentions in Medical Technicians.

Yong Lu, et al. (2017). The relationship between job satisfaction, work stress, work-family conflict, and turnover intention among physicians in Guangdong, China: a crosssectional study. 